\section{Demographic and Clinical Characteristics Associated with Central Nervous System Hemorrhage in Patients with Eosinophilic Granulomatosis with Polyangiitis: A Case Report and Review of the Literature}

\section{To the Editor:}

Eosinophilic granulomatosis with polyangiitis (EGPA) is a systemic antineutrophil cytoplasmic antibodies (ANCA)-associated vasculitis affecting the small- and medium-sized arteries. It is characterized by bronchial asthma often accompanied by pulmonary infiltrates, chronic sinusitis, nasal polyps, and peripheral blood eosinophilia, and occasionally followed by a multisystem vasculitic phase involving several organs. Neurological involvement occurs in 51\%-86\%, usually affecting the peripheral nerves. Conversely, the central nervous system (CNS) is seldom affected $(<10 \%)$. In these cases, cerebral ischemic infarction $(\sim 80 \%)$ and diffuse encephalopathy $(\sim 10 \%)$ have been by far the findings most frequently reported. Published data on EGPA with CNS hemorrhage are limited to anecdotal case reports ${ }^{1-10,11-20,21,22,23,24,25,26}$. We described a case of EGPA presenting with intracerebral hemorrhage (ICH) and did a comprehensive review of the literature. Ethics board approval was not required in accordance with the policy of our hospital.

A 48-year-old man was admitted because of malaise, intermittent low-grade fever, and mild weight loss in the previous 3-4 months. One month before admission he developed numbness with paranesthesia and burning pain in the distal third of his legs. Over the preceding 18 months he referred to a persistent bronchial asthma. He denied a history of traditional cardiovascular risk factors, drug abuse, and trauma. The blood test showed leukocytosis $\left(20.070 / \mathrm{mm}^{3}\right)$, eosinophilia $\left(8.110 / \mathrm{mm}^{3}\right)$, C-reactive protein (CRP; $49 \mathrm{mg} / \mathrm{l}$ ), erythrocyte sedimentation rate (ESR; $52 \mathrm{~mm} / \mathrm{h}$ ), and anti-myeloperoxidase (anti-MPO) antibodies $(128 \mathrm{U} / \mathrm{ml})$. Coagulation variables and an echocardiogram were normal. An electroneurophysiological study showed a severe axonal mixed sensitive-motor polyneuropathy in the lower limbs. EGPA was diagnosed and a 3-day course of intravenous pulses of methylprednisolone ( $1 \mathrm{~g} /$ day) was initiated. On the third day, he suddenly went into a coma and presented a left-sided hemiparesis. A head computed tomography (CT) scan disclosed a large intracranial right-sided frontoparieto-temporal hematoma with midline shift. A CT angiogram excluded vascular malformations and arterial aneurysms. Biweekly intravenous pulses of cyclophosphamide $(500 \mathrm{mg})$ and oral prednisone $(30 \mathrm{mg} /$ day $)$ were started. A month later he partially recovered motility, polyneuropathy completely disappeared, and the size of the hematoma was reduced, but dysarthria remained.

Comprehensive research of the literature on CNS hemorrhage in EGPA was done [MeSH: (Churg-Strauss vasculitis or syndrome) or (eosinophilic granulomatosis with polyangiitis) and (intracerebral, cerebral, intracranial, spinal, subarachnoid, brain $\}$ and (hemorrhage, bleeding, hematoma)]. Finally, 27 case reports were considered suitable for our analysis. Also, our case was added to the series. The description of the 28 cases is summarized in Table 1 and Table 2 .

No differences in sex were observed. The mean age at bleeding presentation in our series $(47 \pm 11 \mathrm{yrs})$ was significantly lower than the mean age of the first event of ICH in the general population $(65 \pm 12 \mathrm{yrs}$ in men, 69.5 \pm 11 yrs in women $)^{27}$. Virtually all patients had systemic low-grade inflammation characterized by increased ESR and/or CRP, leukocytosis, and hypereosinophilia. In addition, the frequency of ANCA-positivity in our series was found to be $\sim 2$-fold higher $(78 \%)$ than expected in patients with general EGPA $(\sim 40 \%)$. These results support the hypothesis that CNS hemorrhage in EGPA may substantially have a vasculitic origin.

The frequency of hypertension (HTN; usually mild to moderate) in our series was $40 \%$, similar to that reported in patients with general EGPA. Therefore, the contribution of HTN to the CNS bleeding in these patients does not seem to be fundamental from a pathophysiological point of view.

In almost all patients, the CNS hemorrhage was preceded by a well-documented diagnosis of EGPA or a history of typical symptoms, with a highly variable interval between both events. The spectrum of clinical manifestation seen in our patients was comparable to that of the largest series and there was no clinical phenotype associated to CNS bleeding.

Several reports have shown a relatively favorable 5-year survival rate (90\%-97\%) for patients with EGPA ${ }^{28}$. In our series, mortality was $15 \%$ (4 of 26 cases). Three deaths occurred within 3 months after bleeding and a fourth at 4 years following a recurrence. So, the estimated 5-year survival rate in our series was $85 \%$ in the best-case scenario. However, the first 2 deaths occurred before 1995, when the overall prognosis of the EGPA was worse than it is currently ${ }^{28}$. Therefore, the short-term prognosis of EGPA patients with CNS bleeding is relatively good and possibly comparable to the rest of patients.

The most important limitation derives from the small number of cases analyzed. However, to our knowledge this is the largest series of patients with EGPA affected by CNS bleeding published in the literature ${ }^{14,17}$.

Despite CNS hemorrhage complicating EGPA being rare $(<1 \%)$, the differential diagnosis of patients with CNS bleeding and some of the following characteristics should be taken into account: (1) relatively young patients, (2) absence of an alternative cause to explain the bleeding, (3) a history of EGPA or some of its typical symptoms, (4) coincidence with constitutional symptoms and/or multisystemic involvement, especially peripheral neuropathy, (5) demonstration of blood inflammatory markers and hypereosinophilia, and (6) positivity for ANCA, especially anti-MPO specificity.

JOSÉ MARIO SABIO, MD, PhD, Systemic Autoimmune Diseases Unit, Department of Internal Medicine, Virgen de las Nieves University Hospital, and Virgen de las Nieves University Hospital, Granada, Spain; MAR RIVERO-RODRIGUEZ, MD, Department of Internal Medicine, Virgen de las Nieves University Hospital, and Virgen de las Nieves University Hospital, Granada, Spain; JOSÉ ANTONIO VARGAS-HITOS, $\mathrm{MD}, \mathrm{PhD}$, Systemic Autoimmune Diseases Unit, Department of Internal Medicine, Virgen de las Nieves University Hospital, and Virgen de las Nieves University Hospital, Granada, Spain. Address correspondence to Dr. J.M. Sabio, Servicio de Medicina Interna, 9th planta Hospital Universitario Virgen de las Nieves, Avda. Fuerzas Armadas No. 2, 18012 Granada, Spain.E-mail: jomasabio@gmail.com

\section{REFERENCES}

1. Maloon A, Fritz VU, Kaplan CL. Neurological complications of systemic vasculitis. A report of 2 cases. S Afr Med J 1985;68:603-5

2. Chang Y, Kargas SA, Goates JJ, Horoupian DS. Intraventricular and subarachnoid hemorrhage resulting from necrotizing vasculitis of the choroid plexus in a patient with Churg-Strauss syndrome. Clin Neuropathol 1993;12:84-7.

3. Liou HH, Liu HM, Chiang IP, Yeh TS, Chen RC. Churg-Strauss syndrome presented as multiple intracerebral hemorrhage. Lupus 1997;6:279-82.

4. Nishino R, Murata Y, Oiwa H, Arakawa T, Sunakawa M, Tsuge M, et al. [A case of Churg-Strauss syndrome presented as right thalamic hemorrhage]. [Article in Japanese] No To Shinkei 1999;51:891-4

5. Ojeda E, Auzmendi A, Teresa Unanue M, Fathi O. [Cerebral hemorrhage in Churg-Strauss syndrome]. [Article in Spanish] Med Clin 2001;116:118-9.

6. Calvo-Romero JM, del Carmen Bonilla-Gracia M, Bureo-Dacal P. Churg-Strauss syndrome presenting as spontaneous subarachnoid haemorrhage. Clin Rheumatol 2002;21:261-3.

7. Tyvaert L, Devos P, Deloizy M, Belhadia A, Stekelorom T. [Peripheral and central neurological manifestations in a case of Churg Strauss syndrome]. [Article in French] Rev Neurol 2004;160:89-92.

8. Sakamoto S, Ohba S, Eguchi K, Shibukawa M, Kiura Y, Okazaki T, et al. Churg-Strauss syndrome presenting with subarachnoid hemorrhage from ruptured dissecting aneurysm of the intracranial vertebral artery. Clin Neurol Neurosurg 2005;107:428-31. 


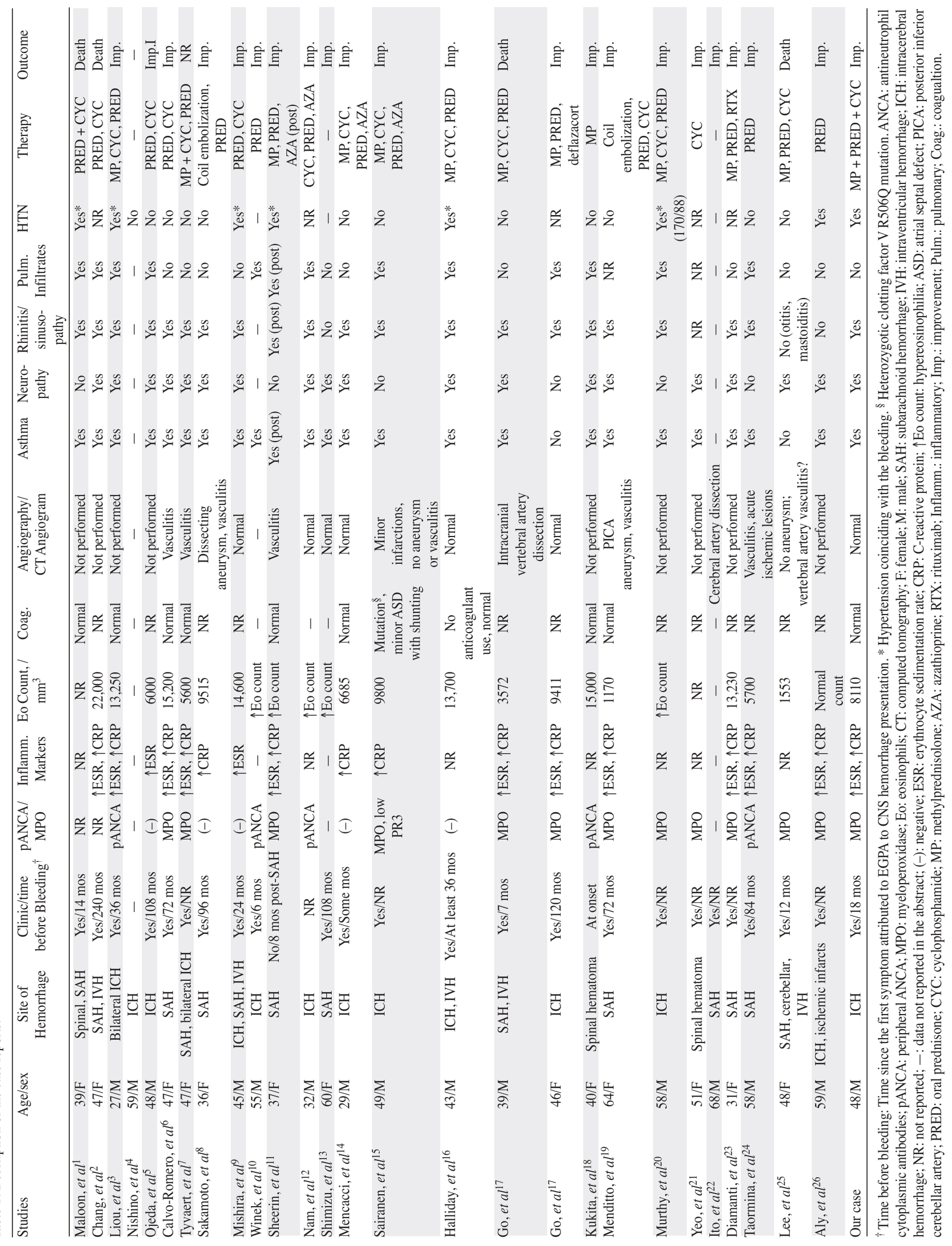
Personal non-commercial use only. The Journal of Rheumatology Copyright $\odot$ 2017. All rights reserved. 
Table 2. Characteristics of EGPA patients with CNS hemorrhage. Values are $\mathrm{n}(\%)$ unless otherwise specified.

\begin{tabular}{|c|c|}
\hline Characteristics & Values \\
\hline \multicolumn{2}{|l|}{ Age at bleeding presentation, yrs } \\
\hline Mean \pm SD & $47 \pm 11$ \\
\hline Median (IQR) & $47(39-57)$ \\
\hline Range, yrs & $27-68$ \\
\hline Male & $15 / 28(53.5)$ \\
\hline \multicolumn{2}{|l|}{ History of EGPA or of any typical symptom of EGPA } \\
\hline Pre-bleeding & $24 / 26(92.3)$ \\
\hline Post-bleeding & $1 / 26(3.8)$ \\
\hline During bleeding & $1 / 26(3.8)$ \\
\hline \multicolumn{2}{|l|}{ Time EGPA, bleeding*, mos } \\
\hline Mean \pm SD & $66 \pm 60$ \\
\hline Median (IQR) & $72(13-102)$ \\
\hline Range & $0-240$ \\
\hline \multicolumn{2}{|l|}{ Site of hemorrhage $e^{\dagger}$} \\
\hline Subarachnoid & $14 / 28(50.0)$ \\
\hline Intracerebral & $13 / 28(46.4)$ \\
\hline Spinal & $3 / 28(10.7)$ \\
\hline Intraventricular & $5 / 28(17.9)$ \\
\hline Multiple location & $8 / 28(28.6)$ \\
\hline Ischemic events coexistence & $3 / 28(10.7)$ \\
\hline \multicolumn{2}{|l|}{ Clinical manifestations ${ }^{\dagger}$} \\
\hline Asthma & $24 / 26(92.3)$ \\
\hline Rhinitis/sinusopathy & $21 / 24(87.5)$ \\
\hline Neuropathy & $19 / 25(76.0)$ \\
\hline Pulmonary infiltrates & $13 / 24(54.2)$ \\
\hline Hypertension & $8 / 20(40.0)$ \\
\hline Inflammatory markers & $17 / 17(100)$ \\
\hline Eosinophilia & $23 / 24(95.8)$ \\
\hline \multicolumn{2}{|l|}{ ANCA } \\
\hline pANCA and/or MPO specificity & $18 / 23(78.3)$ \\
\hline \multicolumn{2}{|l|}{ Angiography/computerized tomography angiogram } \\
\hline Normal & $7 / 17(41.2)$ \\
\hline Vasculitis & $8 / 17(47.1)$ \\
\hline Aneurysm/dissection & $4 / 17(23.5)$ \\
\hline Death & $4 / 26(15.4)$ \\
\hline Poor evolution during the hospitalization & $2 / 4$ \\
\hline Recurrence of bleeding 4 years after first event & $1 / 4$ \\
\hline Recurrence complicated with infective ventriculitis & $1 / 4$ \\
\hline
\end{tabular}

* Elapsed time between onset of EGPA (diagnosis or first typical manifestation) and the hemorrhage occurrence. ${ }^{\dagger}$ Cumulated frequencies. EGPA: eosinophilic granulomatosis with polyangiitis; CNS: central nervous system; IQR: interquartile range; ANCA: antineutrophil cytoplasmic antibodies; pANCA: peripheral ANCA; MPO: myeloperoxidase.

9. Mishra S, Das CP, Das A, Prabhakar S. Intracerebral hemorrhage in a patient with Churg-Strauss syndrome. Neurol India 2007; 55:416-8.

10. Winek J, Zych J, Wiatr E, Oniszh K, Roszkowski-Sliz K. [Stroke as a predominant symptom at Churg-Strauss syndrome]. [Article in Polish] Pneumonol Alergol Pol 2007;75:191-6.

11. Sheerin UM, Barreto J, Brown MM, Brew S, Losseff NA. Subarachnoid haemorrhage as the first clinical manifestation of Churg-Strauss syndrome. J Neurol 2008;255:607-8.

12. Nam TS, Jung HJ, Kim JT, Park MS, Kim BC, Kim MK, et al. Churg-Strauss syndrome complicated with intracranial hemorrhage. J Korean Neurol Assoc 2009;27:257-9.
13. Shimizu K, Ohoba H, Shimada H, Inoue Y, Jinn Y, Yoshimura N. [A case of Churg-Strauss syndrome with subarachnoid hemorrhage and left phrenic nerve paralysis]. [Article in Japanese] Nihon Kokyuki Gakkai Zasshi 2011;49:642-6.

14. Mencacci NE, Bersano A, Cinnante CM, Ciammola A, Corti S, Meroni PL, et al. Intracerebral haemorrhage, a possible presentation in Churg-Strauss syndrome: case report and review of the literature. J Neurol Sci 2011;301:107-11.

15. Sairanen T, Kanerva M, Valanne L, Lyytinen J, Pekkonen E. Churg-Strauss syndrome as an unusual aetiology of stroke with haemorrhagic transformation in a patient with no cardiovascular risk factors. Case Rep Neurol 2011;3:32-8.

16. Halliday J, Herrick A, Leach J. Churg-Strauss, a rare cause of intracerebral haemorrhage. J Clin Neurosci 2012;19:1177-8.

17. Go MH, Park JU, Kang JG, Lim YC. Subarachnoid and intracerebral hemorrhage in patients with Churg-Strauss syndrome: two case reports. J Cerebrovasc Endovasc Neurosurg 2012; 14:255-61.

18. Kukita CC, Gobatto AL, Lobo AZ, Taniguchi LU. Spinal hematoma complicating a Churg-Strauss syndrome patient: a previously unreported association. Clinics 2012;67:855-7.

19. Menditto VG, Di Rienzo A, De Nicola M, Balzano L, Polonara S. Subarachnoid haemorrhage from PICA aneurysm rupture in a Churg-Strauss patient: a case report and a review of the literature. Clin Neurol Neurosurg 2013;115:197-9.

20. Murthy SB, Khalaf N, Shah S, Ma B, Goldsmith CE, Kass JS. Churg-Strauss syndrome: an uncommon cause of intracerebral hemorrhage. JAMA Neurol 2013;70:1580-1.

21. Yeo LL, Shanmugam GN, Thamboo TP, Lahiri M, Rathakrishnan R. Spinal cord haematoma due to Churg-Strauss vasculitis. Rheumatology 2013;52:1213.

22. Ito M, Kato N, Su CC, Kayama T. [A case of Churg-Strauss syndrome with subarachnoid hemorrhage]. [Article in Japanese] Brain Nerve 2014;66:283-8.

23. Diamanti L, Berzero G, Bini P, Ravaglia S, Rognone E, Cavagna L, et al. Spinal hemorrhage in eosinophilic granulomatosis with polyangiitis (Churg-Strauss). J Neurol 2014;261:438-40.

24. Taormina G, Andolina G, Banco MA, Costanza-Gaglio EJ, Bonura A, Buscemi S. An uncommon presentation of eosinophilic granulomatosis with polyangiitis: a case report. J Med Case Rep 2014;8:190.

25. Lee MX, Teng GG, Raju GC, Lim AY. Catastrophic subarachnoid hemorrhage in eosinophilic granulomatosis with polyangiitis without asthma. Int J Rheum Dis 2015 May 11 (E-pub ahead of print)

26. Aly Z, Libman R, Seidman R, Arora R, Siller K, Salamon E, et al. Ischemic and hemorrhagic strokes due to eosinophilic granulomatosis with polyangiitis. J Stroke Cerebrovasc Dis 2015; 24:e279-82

27. Fogelholm R, Murros K, Rissanen A, Avikainen S. Long term survival after primary intracerebral haemorrhage: a retrospective population based study. J Neurol Neurosurg Psychiatry 2005;76:1534-8.

28. Comarmond C, Pagnoux C, Khellaf M, Cordier JF, Hamidou M, Viallard JF, et al; French Vasculitis Study Group. Eosinophilic granulomatosis with polyangiitis (Churg-Strauss): clinical characteristics and long-term followup of the 383 patients enrolled in the French Vasculitis Study Group cohort. Arthritis Rheum 2013;65:270-81.

J Rheumatol 2017;44:9; doi:10.3899/jrheum.160886

$$
\text { Personal non-commercial use only. The Journal of Rheumatology Copyright (C) 2017. All rights reserved. }
$$

